\title{
BMJ Open Developing assistive robots for people with mild cognitive impairment and mild dementia: a qualitative study with older adults and experts in aged care
}

\author{
Mikaela Law, ${ }^{1}$ Craig Sutherland, ${ }^{2}$ Ho Seok Ahn, ${ }^{2}$ Bruce A MacDonald, ${ }^{2}$ \\ Kathy Peri, ${ }^{3}$ Deborah L Johanson, ${ }^{1}$ Dina-Sara Vajsakovic, ${ }^{1}$ Ngaire Kerse, ${ }^{4}$ \\ Elizabeth Broadbent ${ }^{๑ 1}$
}

To cite: Law M, Sutherland C, Ahn HS, et al. Developing assistive robots for people with mild cognitive impairment and mild dementia: a qualitative study with older adults and experts in aged care. BMJ Open 2019:9:e031937. doi:10.1136/ bmjopen-2019-031937

- Prepublication history for this paper is available online. To view these files, please visit the journal online (http://dx.doi org/10.1136/bmjopen-2019031937).

Received 27 May 2019 Revised 20 August 2019 Accepted 28 August 2019
Check for updates

(C) Author(s) (or their employer(s)) 2019. Re-use permitted under CC BY-NC. No commercial re-use. See rights and permissions. Published by BMJ.

For numbered affiliations see end of article.

Correspondence to Dr Elizabeth Broadbent; e.broadbent@auckland.ac.nz

\section{ABSTRACT}

Objectives This research is part of an international project to design and test a home-based healthcare robot to help older adults with mild cognitive impairment (MCl) or early dementia. The aim was to investigate the perceived usefulness of different daily-care activities for the robot, developed from previous research on needs.

Design Qualitative descriptive analysis using semistructured interviews. Two studies were conducted. In the first study, participants watched videos of a prototype robot performing daily-care activities; in the second study, participants interacted with the robot itself.

Setting Interviews were conducted at a university and a retirement village.

Participants In study 1, participants were nine experts in aged care and nine older adults living in an aged care facility. In study 2, participants were 10 experts in aged care.

Results The themes that emerged included aspects of the robot's interactions, potential benefits, the appearance, actions and humanness of the robot, ways to improve its functionality and technical issues. Overall, the activities were perceived as useful, especially the reminders and safety checks, with possible benefits of companionship, reassurance and reduced caregiver burden. Suggestions included personalising the robot to each individual, simplifying the language and adding more activities. Technical issues still need to be fixed.

Conclusion This study adds to knowledge about healthcare robots for people with $\mathrm{MCl}$ by developing and testing a new robot with daily-care activities including safety checks. The robot was seen to be potentially useful but needs to be tested with people with $\mathrm{MCl}$.

\section{INTRODUCTION}

Dementia is a progressive disease that goes through several clinical stages. ${ }^{1}$ Mild cognitive impairment (MCI) refers to a state of cognitive decline that is greater than in normal ageing but does not meet the
Strengths and limitations of this study

- Strengths include the use of two iterations of the study, where the robot was improved after the first feedback.

- Another strength was the inclusion of older adults from an aged-care facility and experts in aged care.

- The second study included face-to-face interactions with the robot in a rest-home setting allowing for ecological validity.

- Limitations included the cross-sectional design, the short time to interact with the robot and the lack of participants with cognitive impairment or informal caregivers

criteria for dementia. ${ }^{1}$ Older adults with MCI demonstrate subtle impairments in memory, thinking and executive functioning that can affect complex occupational or social activities. ${ }^{2}$ Although MCI does not always lead to dementia, it is a risk factor. Mild dementia (MD) represents a later stage of disease, in which individuals have clear deficits in cognition and experience difficulties performing activities of daily living.

When an individual's ability to perform daily activities is impaired, their autonomy becomes limited, and they may require assistance from aged care services. For example, patients have difficulty with managing medication, ${ }^{3}$ keeping appointments, daily schedules and performing daily activities, ${ }^{4}$ psychological decline and distress ${ }^{5}$ and obtaining help in emergencies. ${ }^{6}$ Problems with memory and orientation also raise concern for patient safety and the ability to care for oneself within one's own home. ${ }^{7}$ These difficulties can be a burden on the individual, their carer and the healthcare system.

Current strategies to reduce the burden on the healthcare system prioritise ageing 
in place. This is where older adults are able to live independently in their own homes safely. ${ }^{8}$ It is therefore important to find ways for older adults with MCI or MD to remain in their home environment and maintain autonomy in their daily lives and assistive technologies may be useful in this regard. ${ }^{910}$ One possible technology is a healthcare robot programmed to promote and monitor a person's health, aid with daily living, ensure their safety when living alone and potentially reduce further cognitive or physical decline. ${ }^{711}$ These robots have the potential to reduce the growing burden placed on caregivers and the healthcare system. ${ }^{12}$

A recent review describes the needs of older adults including functional, physical and cognitive decline, health management, and social and psychological needs. It describes 23 different robots that may meet these needs, including both companion and assistive robots. ${ }^{7}$ The seal robot Paro has been shown to provide companionship and reduce loneliness, ${ }^{13}$ psychological stress, ${ }^{14}$ stress hormones ${ }^{1516}$ and blood pressure. ${ }^{17}$ More assistive robots include Care-O-Bot, Wakamaru, Cafero, iRobiQ and Ifbot. ${ }^{7}$ Each of these robots is designed to assist older adults with their daily activities in different ways, such as providing reminders and health monitoring. Of these, the only robot still in production is Care-O-Bot, which can also be used as a mobile information centre in museums, stores and airports.

There is little research investigating the use of assistive robots in older adults with MCI or MD in particular. An assistive robot specifically designed for this population could enable people to live at home for longer, as they do not yet need full-time care like patients with full dementia. Robots designed to provide support specifically to people with MCI and tested with these patients include CompanionAble and RobuLAB10, both tested in Europe. CompanionAble is a robot that links to a smart home environment to allow people living with MCI to remain at home alone. ${ }^{18}$ This robot focuses on cognitive and social support and includes reminders, suggesting activities, cognitive training and video calling. CompanionAble has been tested with five couples in their homes over 2 days. Participants with MCI or dementia perceived this robot as enjoyable and useful, and caregivers reported a reduction in burden. This research project has now finished. RobuLAB10, a prototype robot, can make calls, monitor emotions and health, help in emergencies, provide cognitive training and provide support for daily activities. ${ }^{19}$ Following a 2-hour demonstration, participants noted the potential benefits of the robot; carers and those with MCI perceived it as more useful than healthy older adults did.

These studies demonstrate that homecare robots could be useful for patients with MCI or MD in the home environment. However, assistive robots are not yet functional enough for successful commercial adoption with older adults with MCI. Questions remain over which activities a robot could perform and how these are perceived. New, more sophisticated robots are emerging, and the current research adds to this body of literature by developing and testing a new healthcare robot specifically for this population in the Asia-Pacific region.

This paper reports the results from the second phase of a 5 -year project to develop a home-based healthcare robot for older adults with MCI or MD. The first phase investigated the opinions of older adults, carers and experts in aged care about the needs of older adults with MCI and how a robot could assist. ${ }^{20}$ Four broad themes emerged to provide help with daily schedules including reminders about routines and reassurance, to assist with safety checks and respond to emergencies, to monitor health and well-being and to provide activities for therapeutic intervention, including cognitive, physical and social stimulation. A robot was developed based on these identified needs and informed by previous literature. ${ }^{713}$ This robot differs from previous healthcare robots, in that it was designed to assist older adults with daily activities such as waking up, going to bed and checking for safety hazards like the stove being left on or windows left open.

The aim of this phase of the research was to investigate the perceived usefulness of these daily-care activities when demonstrated on a robot to help people with MCI and MD in their own homes, from the perspective of older adults living in a retirement facility and experts in aged care. These experts were familiar with older patients' needs, so were able to provide informed advice. Older adults living in an aged care facilities often interact with peers and family members experiencing cognitive decline and have age-related health conditions themselves, such as impaired hearing or vision or the need to take medication, so can also provide an informed perspective.

Two studies were conducted. In the first study, videos of the robot were shown to the participants. From the results of this first study, the robot programming was adjusted. In the second study, participants interacted with the robot in real-time.

\section{METHODS}

A qualitative design was used to gather rich information from participants. Methods are reported using the Standards for Reporting Qualitative Research (SRQR) guidelines. ${ }^{21}$ Approval was obtained by University of Auckland Human Participants Ethics Committee for both studies.

\section{Reflexivity}

The researchers were a group of engineers, computer scientists, psychologists and medical professionals. Although the interviewers did not have a prior relationship to participants, some of the other researchers were known to the expert participants. This facilitated recruitment, but may potentially have increased bias. The researchers performing the analysis included a computer scientist and two psychology researchers, and interpretations of the data were informed by these perspectives. 


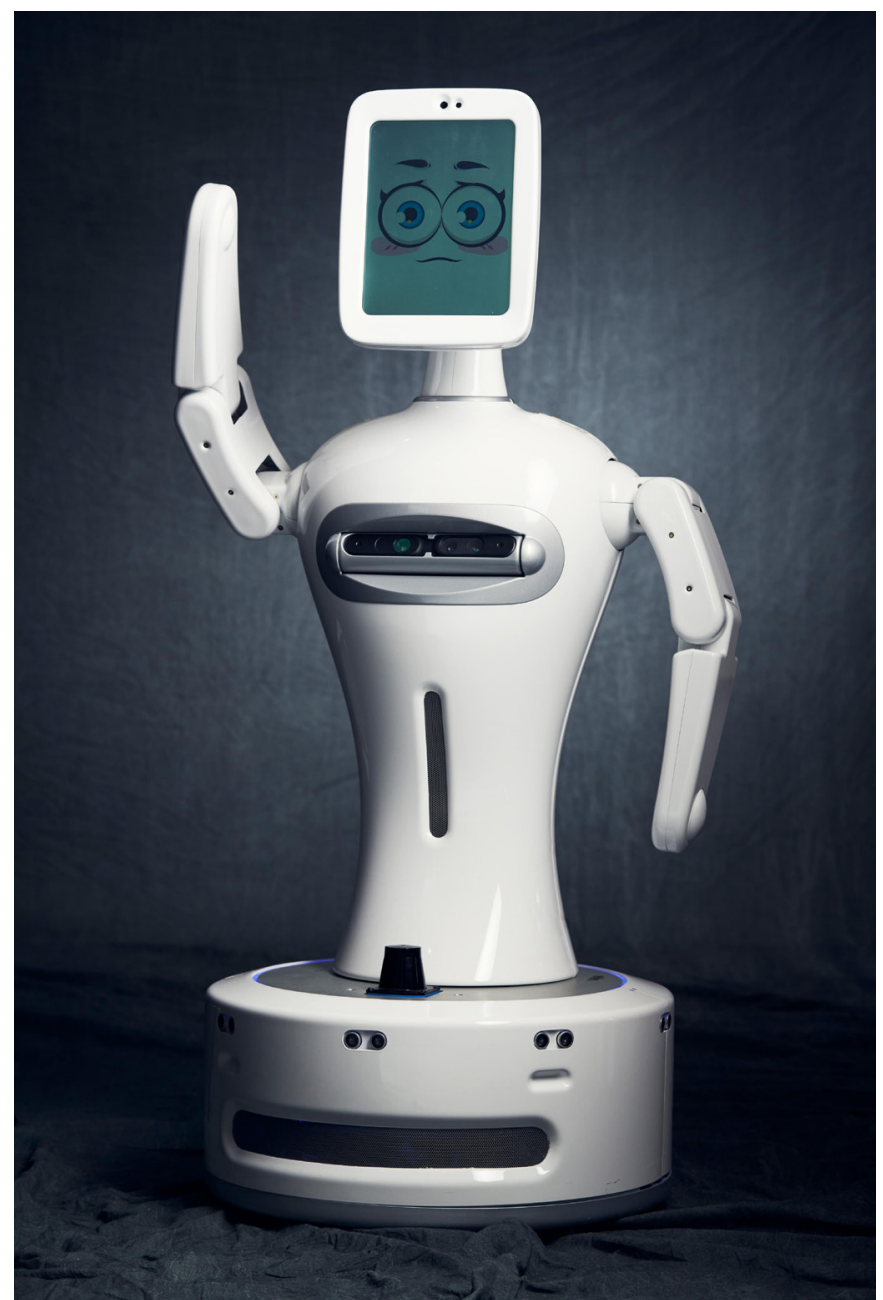

Figure 1 Photograph of the Silbot robot used in the study (photograph courtesy of Lee Howell).

\section{Patient and public involvement}

This research was done without patient involvement in the design phase. Patients were not invited to comment on the study design and were not consulted to develop patient relevant outcomes or interpret the results. Patients were not invited to contribute to the writing or editing of this document for readability or accuracy.

\section{STUDY 1 METHOD}

\section{Study design}

This descriptive qualitative study used semistructured interviews with experts in aged care and older adults living in a large retirement facility (Selwyn Village), which includes independent living apartments, nursing homes and hospitals, as well as a secure dementia unit, with a total of 560 residents. Dates of data collection were 5 October 2017 to 27 April 2018. Data were not collected on the health status of participants.

\section{Sample and site}

A sample of older adults ( $n=9$ total; five females and four males) and experts in aged care $(n=9$; six females and three males) was recruited via convenience sampling. The experts were nursing home directors, nurses and doctors (including psychiatrists and geriatricians) who worked in clinical aged care settings. All of the experts had worked in aged care for at least 10 years and had cared for people with MCI and dementia. Two of the experts had been involved in the first phase of the research that involved interviews $^{20}$ and had interacted with aged care robots previously. Older adults were recruited from the retirement village using leaflets and word of mouth. Recruitment finished when data saturation was reached.

\section{Procedure}

Six daily-care activities were designed and implemented on a Silbot robot, shown in figure 1 . The activities were developed by the authors of this paper to represent examples of the key themes identified in phase 1 of the project $^{20}$ : help with daily schedules (two videos), safety and security (two videos), monitoring health and wellbeing (one video) and therapeutic interventions (one video). Therapeutic interventions refer to physical, social and cognitive activities to help reduce progression of illness. The Silbot is made by Robocare, Korea, with a head (a pan-tilt touch screen), camera, microphones, two arms for making gestures and a wheeled mobile base that has sensors for navigation. The Silbot is capable of interacting with the user by voice interface and also using the touch screen. ${ }^{22}$ This robot was chosen because it is currently produced and was developed for older adults by Robocare, a partner in this research. The robot was semiautonomous; where possible the robot would perform the interactions by itself. At times, there were issues with speech recognition, which required the interviewer to send the correct text to the robot. For example, if the participant had a strong accent, the robot could not understand the speech.

The six activities were as follows:

\section{Wake up}

The robot is programmed to wake the person up at a set time, state the time and date, and ask if they are ready to get up. The robot reads the person's schedule for the day and the schedule is displayed on its screen.

\section{Mood check}

Once a day, the robot asks the user about their mood by displaying a face scale $^{23}$ on the screen and inviting the user to touch the face that best represents their current mood. This provides a record of psychological health, and the robot is programmed to provide an appropriate response if the user is feeling down, 'sorry to hear you are not feeling so good today'. It also offered a list of activities that a person could do to improve their mood (eg, go for a walk, listen to music or call a friend). A longer depression questionnaire ${ }^{24}$ is given to the person if they report a negative mood for seven consecutive days. All of this was included in the video. The mood results would be available to caregivers if this robot was used in a real situation. 


\section{Safety checks}

The robot prompts the user through a series of safety checks at three time points; when leaving the house, after a meal and before retiring to bed. These checks ask the person to turn off any appliances that may pose a safety risk (eg, the stove) and to check they have locked the doors and closed the windows before leaving the house.

\section{Medication reminding}

The robot reminds the patient when it is time to take their medication and which medications to take and how. If the patient does not take their medication, the robot asks them why and this information is sent to the appropriate person for follow-up.

\section{Therapeutic interventions}

The robot prompts and guides the user through physical exercises or cognitive training games at regular intervals defined for each user.

\section{Emergency}

If the person calls for help, the emergency scenario is activated and the robot will move to the person and ask if they need help. The robot will call the patient's nominated phone number for assistance if needed.

A male middle-aged adult actor was filmed going through each of the activities with the robot at the University of Auckland. Six videos were shown to participants that varied in length from 1 to 3 min (total for all videos was $11 \mathrm{~min}$ ). The videos were shown in sequence and participants were asked questions after each one. Videos were used in this first study, as opposed to the live robot, as we wanted to gain initial feedback during the development of the robot so that the robot could be further refined before being tested live. The videos were realistic in terms of robot's capabilities, although speech recognition always worked in the videos, whereas it sometimes failed in reality.

The participants had 30-60 min semistructured interviews that were conducted either at the University of Auckland or Selwyn Retirement Village. Study information was provided to participants, and written informed consent was obtained prior to each interview. A $\$ 10$ petrol voucher was given to each participant as a token of appreciation at the end of the session.

The research assistant explained each activity one by one and showed the video-recording of the robot interacting with an actor. After each activity, the participants were asked open-ended questions about their opinions of the robot including questions about: their general thoughts, likes and dislikes, how useful this activity would be for someone with MCI or MD, how easy this activity would be to use and understand for a person with MCI or $\mathrm{MD}$ and any improvements they could suggest.

These responses were recorded using an audio recorder and then transcribed by a research assistant. The transcribed interviews were then coded using qualitative analysis by two independent researchers (MML, CS) to identify key themes. A qualitative descriptive analysis was conducted. ${ }^{25}$ The themes were not decided prior to analysis. Two researchers independently read and re-read the transcripts of the interviews, made notes in the margins and extracted emergent themes. The two researchers met to discuss themes and made an agreed list of master themes by clustering some of the emerging themes together. Both researchers then used the master list to re-code the interviews. There were few differences between the researchers after this process. A summary account of the participants' views was then reported, using verbatim quotes to support the researchers' interpretations.

\section{STUDY 1 RESULTS}

Four key themes were identified, which are shown in table 1 with example quotations and described below.

\section{Interactions}

The first overall theme that emerged was comments about the interaction itself. This included comments about the importance of showing text on the screen, as well as needing a bigger screen and buttons. Participants thought the robot spoke too quickly and the interaction could be slowed down, giving the steps one by one, giving people more time to respond and repeating answers to check understanding. Some participants wanted the robot to give directive instructions, whereas others suggested the robot gives options so users could make their own choices. Some suggested the robot could be more chatty and conversational, more friendly, less patronising and more respectful. The language could be less formal using words like pills instead of medication, and the 'menu' screen should be given another, more familiar name. Some thought the voice could be given a New Zealand accent, be clearer and the volume could be louder. The ability to interact via voice was seen as positive, but older adults might also need to be reminded that they could press buttons on the screen.

\section{Benefits}

The second theme that emerged was perceived benefits from the robot. Most commented that the activities were beneficial and would be useful for people with MCI, including the reminders, exercise prompts, emergency response, offering reassurance, safety checks and keeping a routine. A subtheme that emerged was that the robot could become a friend as it offered social support and companionship.

\section{The robot}

Another theme concerned the robot itself, its appearance and actions. Some questioned the need to have a robot and that a smart house or a diary could do these functions. Some liked the human-like aspects of the robot's appearance and suggested this might help with building a relationship, whereas others liked its robotic aspects and did not want it to be human-like. Some thought the eyes 
Table 1 The four themes identified from interviews with quotations from experts and older adults in study 1

\begin{tabular}{|c|c|c|}
\hline Theme & & Example quotes \\
\hline Interactions & $\begin{array}{l}\text { Older Adults (quotes } \\
3 \text { and } 4 \text { ) }\end{array}$ & $\begin{array}{l}\text { "I liked that you can respond to it. One of the most important things to me is } \\
\text { that you are responding to the robot and you don't actually have to touch the } \\
\text { screen all the time." } \\
\text { "I think it would be very important to have a New Zealand voice. Could be } \\
\text { quite disorienting for people to have to interpret an accent, depending on the } \\
\text { progression of the condition." } \\
\text { "If they were serious, I don't think they would be able to follow that. Truthfully } \\
\text { anyway. They might just push a button in the hopes something would } \\
\text { happen." } \\
\text { "I think he could speak more clearly. Some of the consonants I found difficult } \\
\text { to understand." }\end{array}$ \\
\hline Benefits & $\begin{array}{l}\text { Older Adults (quotes } \\
3 \text { and } 4 \text { ) }\end{array}$ & $\begin{array}{l}\text { "All you have to do is call out help and the robot will come. I think that is very } \\
\text { clever. In fact, the whole robot scenarios are very clever." } \\
\text { "It is one of the things that will be helpful to keep people in their homes is } \\
\text { making sure it is safe enough. So, I do think it is a task for the robot." } \\
\text { "I think to remind you to exercise is very good. Otherwise you will sit there } \\
\text { and get stagnant." } \\
\text { "It would give them a regularity that would take a huge amount of anxiety } \\
\text { away at the beginning of each day." }\end{array}$ \\
\hline The robot & $\begin{array}{l}\text { Experts (quotes } 1 \\
\text { and 2) } \\
\text { Older Adults (quotes } \\
3 \text { and 4) }\end{array}$ & $\begin{array}{l}\text { "The arms are distracting. It would be really important to see what a person } \\
\text { with dementia would do with it, what grab them?" } \\
\text { "I wonder about those big eyes; it might be a bit scary for an old person." } \\
\text { "I haven't noticed the arms of the robot before. It was wonderful that I felt it } \\
\text { was interacting." } \\
\text { "Make it more human. It's very casual because the person could put old } \\
\text { clothing on top, that's fine." }\end{array}$ \\
\hline Improve functionality & $\begin{array}{l}\text { Older Adults (quotes } \\
3-5)\end{array}$ & $\begin{array}{l}\text { "The questions are too long and one after the other means you don't have } \\
\text { the time to think or respond well." } \\
\text { "Also, remind people to wash, get cleaned up and ready for breakfast and } \\
\text { this kind of thing. Sometimes for dementia people, they forget to do all these } \\
\text { kinds of things." } \\
\text { "If they can put in the items they need, it would be more useful and } \\
\text { customisable. There are different needs for different people." } \\
\text { "Could it make some music and make it more homely, some background } \\
\text { music when it is not giving the orders." } \\
\text { "Well I think they would have to be tried to know. Yes, because there's all } \\
\text { grades of dementia as well isn't there. And some would need more help than } \\
\text { others." }\end{array}$ \\
\hline
\end{tabular}

and face looked worried or scary. Many commented that the arms did not have much purpose, were distracting and their movement too noisy. It was suggested the robot turn to face the user more.

\section{Improve functionality}

The fourth theme was suggestions to improve the functionality of the robot. This included adding video calling to family and medical services. The emergency scenario needed to ask more details on why the user needed help and have a greater sense of urgency. Some people commented on what the robot should do if a person does not want to take their medication. They thought the follow-up of asking why they did not want to take their medication was a good addition.

Suggestions included adding more reminders (such as doing the dishes), repetition of reminders, more instructions and details, orienting people more to the time and day, suggestions for what to wear, adding music and adding more stimulating activities. Other ideas were for the robot to follow the person when they did the safety checks, conduct fewer safety checks (only the most important ones) and rescheduling exercise sessions if the person did not want to do them. The depression questionnaire was seen as too long and negatively focused. Some thought the timing and content of the reminders needed to be personalised to the user and their stage of dementia. Some suggested the robot could learn about the user and adapt its behaviour as it learns. Participants also mentioned various issues that could be useful to include on the robot, such as detecting infections, falls or delirium. Finally, the importance of testing the robot with people with MCI or dementia was emphasised. 


\section{STUDY 2 METHOD}

\section{Study design}

This descriptive qualitative study used semistructured interviews with experts in aged care. Dates of data collection were 31 October 2018 to 23 November 2018.

\section{Sample}

A sample of experts in aged care $(n=10$; nine females and one male) was recruited directly by the researchers. These experts were selected through pre-existing relationships held by the research team and either had experience working with or researching individuals with MCI or MD for at least 10 years. Five had participated in study 1 (two of whom had interacted with robots before). Six interviews were conducted with a single participant, two interviews were conducted with two participants in each. Five participants were New Zealanders, and there was one German, one American, one Mexican, one South African and one Belgian. Data on age of participants were not collected.

Recruitment finished when data saturation was reached.

\section{Procedure}

The suggestions made by the experts and older adults in the first study were reviewed and implemented into the activities on the Silbot robot, including slowing and simplifying the speech and language, adding more instructions and more reminders, improving speech recognition and replacing the 15-item depression questionnaire with a shorter two-item questionnaire that has been well-validated. ${ }^{26}$ The ability to respond to simple questions, such as the time of day, was also added. The face was changed and the buttons on the screen made bigger.

In the second study, the following five activities were tested: wake-up, self-report mood, safety checks, medication reminding and person-initiated interactions (including the emergency scenario from the first study and responding to questions). The therapeutic intervention activity was not implemented into the Silbot for the second study due to technical limitations (the exercise instructions would not play on the robot and there was a lack of time to fix this). Interactions for each activity varied between 2 and $6 \mathrm{~min}$, and the total interaction time with the robot was $16-20 \mathrm{~min}$. The robot was autonomous and sometimes did not understand the participant so the utterance had to be repeated, which explains the variance in interaction time between participants.

The expert completed a 60-90 min semistructured interview in the library of the nursing home at Selwyn Retirement Village. After giving written informed consent, each expert interacted with the robot for all five activities using voice commands or touching the screen. After each activity, the experts were asked open-ended questions about the perceived usefulness of the robot's activities for patients with MCI or MD, including questions about their general likes and dislikes, whether they thought the activity would be useful for someone with MCI or MD, how easy the activity would be to use and understand for someone with MCI or MD and any suggestion for improvement. A $\$ 10$ petrol voucher was provided at the end of the session.

The responses to the questions were voice-recorded and later transcribed by a research assistant. Three independent researchers (MML, D-SV, CS) then coded the interviews using qualitative descriptive analysis to identify key themes using the same procedure as study 1 . The themes were not decided from study 1 , but emerged independently from the analysis of transcripts from study 2.

\section{STUDY 2 RESULTS}

The emergent themes are described below, and table 2 includes representative quotations from each theme.

\section{Interactions}

The first theme that emerged concerned the interactions with the robot. People liked their simplicity and thought they were easy to use and were not overloading. They liked the clear screen, big buttons and voice activation. People liked the variety of response options, but were curious about what would happen if the person wanted to answer in a way that was not an available option. Again, some commented that the speech was too fast, needed to be louder and the robot needed to give people more time to respond. Participants also commented that the robot should suggest rather than command and there should be the addition of please and thank you.

\section{Benefits}

The second theme to emerge was perceived benefits from the robot. Many commented that they liked the concepts behind the scenarios and that they were useful for people with MCI/MD. They thought the interaction was stimulating, especially the face and arm movements, and could arouse curiosity and interest. Many liked the reminders and prompts, as they triggered memory, as well as the fact that the robot helped with reorientation to time and place, and scheduling the day. Participants mentioned these activities could help with reducing anxiety and providing reassurance.

Again, companionship emerged as subtheme, with comments that the robot could make users feel as if there was someone there to support them, and it felt like you were building a relationship with the robot. Participants suggested the robot could be even more interactive and this might reduce loneliness.

Some commented that they could imagine the robot being used in real life, that it had a lot of potential and they were excited to see if it could become integrated with existing technologies. They suggested the robot might decrease carer burden.

\section{The robot}

The third theme regarded the robot itself. Many commented that the face and body language humanised the robot. They thought the voice sounded empathetic 
Table 2 Themes and example quotations from the interviews with experts from study 2

\begin{tabular}{|c|c|}
\hline Theme & Example quotes \\
\hline Interactions & $\begin{array}{l}\text { "I think it goes a little too fast for an older } \\
\text { person." } \\
\text { "I like the questions it was asking and I think } \\
\text { it was all quite manageable for someone with } \\
\text { dementia." } \\
\text { "I think the voice, if it was a bit more natural, a } \\
\text { bit more human, maybe if it was an actual voice } \\
\text { recording instead of an automated voice." }\end{array}$ \\
\hline Benefits & $\begin{array}{l}\text { "I think just having the reminder with the time can } \\
\text { be quite helpful for someone that just can't quite } \\
\text { remember the checkpoints of the day, is not } \\
\text { exactly sure about the passage of time, but can } \\
\text { still do these tasks." } \\
\text { "I think they will mostly feel like somebody is } \\
\text { there for them and somebody is caring for them } \\
\text { even though it's not a human being. But they } \\
\text { have someone to interact with which is quite } \\
\text { good." } \\
\text { "I think it was trying to duplicate the basic needs } \\
\text { of a person with MCl." }\end{array}$ \\
\hline The r & $\begin{array}{l}\text { "I really liked the arm movements and the face. } \\
\text { I think those do a really good job at, better than } \\
\text { I would expect, at giving it some more human } \\
\text { qualities." } \\
\text { "The robot is quite friendly; it's not intimidating at } \\
\text { all. It feels nice and warm and fun." } \\
\text { "I really liked the arm movement. The before } \\
\text { bed tap on the head was really nice. It really } \\
\text { humanises it in a really interesting way." }\end{array}$ \\
\hline e nality & $\begin{array}{l}\text { "You want to be tailoring this to the person, you } \\
\text { will need to know some things that will trigger } \\
\text { them to do things." } \\
\text { "There are too many faces. I can tell you, working } \\
\text { with persons with intellectual disability." } \\
\text { "I think it would be a good idea if they include a } \\
\text { little bit more of the activities in daily living. They } \\
\text { have asked brushing your teeth, but add things } \\
\text { like bathing." }\end{array}$ \\
\hline $\begin{array}{l}\text { Technical } \\
\text { difficulties }\end{array}$ & $\begin{array}{l}\text { "Technical difficulties would make a person with } \\
\text { dementia pretty confused so it would need to be } \\
\text { able to run quite smoothly." } \\
\text { "I think there are times where it doesn't quite } \\
\text { register the voice or answers too quickly but I } \\
\text { think that's solvable." } \\
\text { "Obviously my accent seems to be a challenge } \\
\text { for the robot." }\end{array}$ \\
\hline
\end{tabular}

$\mathrm{MCl}$, mild cognitive impairment.

and friendly and liked that the robot turned to face towards you during the interaction. On the contrary, some people thought that the voice was too automated, that the movement was too loud and not smooth enough and that it looked too robotic with a hard body. Some thought there were too many distracting arm movements, face changes and flashing lights, which could overload someone with cognitive impairment.

\section{Improve functionality}

The fourth theme included suggestions to improve the functionality of the robot. This included adding more options of things to do (such as games, audio books, music and videos), more reminders for bathing, toileting, cleaning, brushing teeth and turning of lights. Some wanted further prompting, such as, 'are you still thinking about my question?' In regard to mood assessment, some thought that the two depression questions could be difficult for people with cognitive impairment to understand and that providing fewer face options could be an improvement.

Again, personalisation emerged and the need to cater to the different stages of cognitive impairment and to individuals' needs. Some wanted more detailed medication reminders. It was suggested that the robot be tested with people with MCI and that it may only be useful for older adults who were already familiar with technology.

\section{Technical difficulties}

The final theme that emerged was technical difficulties. People said there were problems with voice recognition (especially for people with accents) and that the robot needed to be more flexible with the words you could use for the voice recognition to work. Others mentioned problems with pressing the touch screen. The participants stressed the importance of fixing these issues to improve functionality of the robot.

\section{DISCUSSION}

The aim of this research was to investigate the perceived usefulness of daily-care activities implemented on a robot to help people with MCI and MD remain at home. The results indicated that both older adults and experts thought the activities would be useful for people with MCI and MD and possibly provide companionship, stimulation, reassurance and reduce caregiver burden. However, a number of improvements were suggested for how the robot interacted with the user, the functions of the robot, its appearance and movements, and the need to fix technical limitations. The participants also mentioned the need for personalisation of the robot to each user, and most perceived the humanisation of the robot positively especially in the second study.

These findings integrate with previous research on user's experiences of homecare robots for patients with MCI or MD. ${ }^{18}{ }^{19}$ Similar to the current research, a previous study also found that participants suggested putting further reminders and activities on the robot, and users experienced technical issues with the touch screen and voice recognition. ${ }^{18}$ However, the participants in that study formed closer relationships with the robot since they were able to interact with it over 2 days, and carers saw it as more useful than did people with MCI.

The findings add to previous knowledge about what types of activities and interactions are seen as useful. Applications for cognitive support and for everyday tasks were also seen as important in a study by Pino et $a l,{ }^{19}$ although some of the activities in that study, such as online grocery shopping and journey planning, were different to those in this study. Adding to previous studies, this research shows 
that safety checks could be a useful activity for a robot and checks should be given with simple and slow instructions for each step, following the person and checking for understanding. Any questions about mood need to be kept simple; too many options may be too complicated for people with MCI.

It appears that robots will need to be personalised to the users' stage of cognitive impairment, their medications, abilities and preferences for activities. This important point has also been found by previous research. For example, differences between users in their ability to use a virtual keyboard show that personalisation of interfaces is required. ${ }^{18}$ Pino et al also discuss the importance of personalisation to the user's capabilities, needs and preferences. $^{19}$

Although the importance of personalisation of a robot to the user's culture did not emerge in this research, culture is a critical consideration for the design of these robots. On a practical level, a robot needs to 'speak' the same language as a user and to refer to culturally appropriate items, such as food and clothing. Research has shown that people from different countries have different assumptions about robots ${ }^{27}$ and that people have biases towards robots they perceive as from their own culture. ${ }^{28}$ This suggests that robots may need to be culturally tailored.

In the current research, the human-like aspects of the robot were seen favourably for companionship by the experts, whereas older adults had mixed opinions. These findings add to discussion in the literature around the importance of considering human-like aspects of social robots. ${ }^{29}$

Methodological considerations include the analysis of the data by a mix of researchers who had experience in computer science and psychology. Analysis by more than one researcher independently can help to increase trustworthiness as the themes were discussed and agreed on. Conducting two studies, holding onsite team meetings, describing our methods and keeping an audit trail of documents on a secure shared drive also helped increase trustworthiness. ${ }^{30}$ The same themes emerged independently from the two studies, and this is probably because both studies showed the same robot doing very similar activities. The second study found more comments about technical difficulties, and this is probably because participants experienced more technical problems when interacting with the robot than when watching videos in the study 1 .

However, the two present studies were limited by their cross-sectional design and participants had little time to interact with the robot. Furthermore, only one kind of robot was used in both studies. The first study was limited by use of videos; however, the second study included real-time interactions with the robot. Many participants mentioned aspects with Silbot's appearance and movements, and we may have had different results if we had used a different robot. However, sufficient feedback was obtained regarding the activities themselves, which are applicable to other robots with a screen and voice and able to deliver the activities. A further limitation was the lack of participants who had MCI or informal caregivers of people with dementia. Informal caregivers were not formally sought as participants for these studies, yet they are likely to benefit from any reduction in caregiving burden that assistive technologies can provide. Nevertheless, many of the older adults did have experience with relatives or friends who had MCI or dementia.

This study also had some strengths. In some health technology research, engineers build a technology and then search for a problem for it to solve. However, in this 5 -year project, the initial stage identified needs relevant to older people with MCI or MD by interviewing older adults, informal caregivers and experts in dementia. ${ }^{20}$ Building on these findings, we developed and tested a robot to assist with these identified needs, and in this second stage tested the robot with experts and older adults. These findings will inform the third stage, where the robot will be tested with patients with MCI and MD. This will be an important next step as this population may have different views. ${ }^{13}$

Implications are that robots for MCI should continue to be further developed because they are seen as potentially useful. However, more work is needed to ensure they are technologically robust, simple, appropriate and usable by people with MCI or MD.

\section{CONCLUSION}

The activities developed for a healthcare robot to assist with waking up, medication reminders, safety checks, measuring mood, dealing with emergency situations and delivering therapeutic interventions were regarded as useful for people with MCI or MD. These results support the activities suggested by previous studies, with the additional finding that a robot could be useful for conducting a safety checklist. Suggestions around the robot's appearance, ability to interact and functionality emerged that may be useful in the future development of robots for this population. Perceived benefits included the potential to reduce loneliness and caregiver burden. There is a need to refine the robot's activities, improve technical issues and test it in the homes of older adults with MCI and MD, in the next phase of the project.

\section{Author affiliations}

${ }^{1}$ Department of Psychological Medicine, The University of Auckland, Auckland, New Zealand

${ }^{2}$ Department of Electrical, Computer and Software Engineering, The University of Auckland, Auckland, New Zealand

${ }^{3}$ School of Nursing, The University of Auckland, Auckland, New Zealand ${ }^{4}$ Department of General Practice and Primary Health Care, School of Population Health, The University of Auckland, Auckland, New Zealand

Contributors ML contributed to the study design, data analysis and writing the paper; CS, DLJ and D-SV contributed to data collection and analysis; HSA and CS contributed to programming the robot; HSA, BAM, KP, NK and EB contributed to study design and funding acquisition and editing the draft. EB and ML made the revisions. 
Funding This work was supported by the Ministry of Trade, Industry and Energy (MOTIE, Korea) under Industrial Technology Innovation Program (No 10063300). Funders played no role in data collection, interpretation or reporting.

Competing interests None declared.

Patient consent for publication Not required.

Provenance and peer review Not commissioned; externally peer reviewed.

Data availability statement № data are available.

Open access This is an open access article distributed in accordance with the Creative Commons Attribution Non Commercial (CC BY-NC 4.0) license, which permits others to distribute, remix, adapt, build upon this work non-commercially, and license their derivative works on different terms, provided the original work is properly cited, appropriate credit is given, any changes made indicated, and the use is non-commercial. See: http://creativecommons.org/licenses/by-nc/4.0/.

\section{REFERENCES}

1. Petersen RC. Mild cognitive impairment. Continuum 2016;22:404-18.

2. Gauthier S, Reisberg B, Zaudig M, et al. Mild cognitive impairment. The Lancet 2006;367:1262-70.

3. Jekel K, Damian M, Wattmo C, et al. Mild cognitive impairment and deficits in instrumental activities of daily living: a systematic review. Alzheimers Res Ther 2015;7.

4. Lindbergh CA, Dishman RK, Miller LS, et al. Functional disability in mild cognitive impairment: a systematic review and meta-analysis. Neuropsychol Rev 2016;26:129-59.

5. van der Roest HG, Meiland FJM, Comijs HC, et al. What do community-dwelling people with dementia need? A survey of those who are known to care and welfare services. Int Psychogeriatr 2009;21:949-65.

6. Meiland F, de Boer ME, van Hoof J. Functional requirements for assistive technology for people with cognitive impairments and dementia. In: Wichert R, Van Laerhoven K, Gelissen J, eds. Constructing ambient intelligence. Aml 2011. communications in computer and information science. Berlin, Heidelberg: Springer, 2012: 277. 146-51.

7. Robinson $\mathrm{H}$, MacDonald $\mathrm{B}$, Broadbent $\mathrm{E}$. The role of healthcare robots for older people at home: a review. Int J Soc Robot 2014;6:575-91.

8. Morley JE. Aging in place. J Am Med Dir Assoc 2012;13:489-92.

9. Span M, Hettinga M, Vernooij-Dassen M, et al. Involving people with dementia in the development of supportive it applications: a systematic review. Ageing Res Rev 2013;12:535-51.

10. Demiris $\mathrm{G}$, Rantz $\mathrm{M}$, Aud $\mathrm{M}$, et al. Older adults' attitudes towards and perceptions of "smart home" technologies: a pilot study. Med Inform Internet Med 2004;29:87-94.

11. Wu Y-H, Fassert C, Rigaud A-S. Designing robots for the elderly: appearance issue and beyond. Arch Gerontol Geriatr 2012;54:121-6.

12. Vandemeulebroucke T, Dierckx de Casterlé B, Gastmans C, et al. The use of care robots in aged care: a systematic review of argumentbased ethics literature. Arch Gerontol Geriatr 2018;74:15-25.
13. Robinson H, MacDonald BA, Kerse N, et al. Suitability of healthcare robots for a dementia unit and suggested improvements. J Am Med Dir Assoc 2013;14:34-40.

14. McGlynn SA, Geiskkovitch D, Mitzner TL, et al. PARO's StressReduction Potential for Older Adults. Proc Hum Factors Ergon Soc Annu Meet 2016;60:1799-803.

15. Nomura T, Hoshina Y. How different types of animal robots differently influence elder and younger people's mental states? in: proceedings of the companion of the 2017 ACM/IEEE International Conference on Human-Robot interaction. ACM 2017:231-2.

16. Saito T, Shibata T, Wada K. Relationship between interaction with the mental commit robot and change of stress reaction of the elderly. in: computational intelligence in robotics and automation 2003:119-24.

17. Robinson $\mathrm{H}$, MacDonald $\mathrm{B}$, Broadbent $\mathrm{E}$. Physiological effects of a companion robot on blood pressure of older people in residential care facility: a pilot study. Australas J Ageing 2015;34:27-32.

18. Schroeter C, Mueller S, Volkhardt M, et al. Realization and user evaluation of a companion robot for people with mild cognitive impairments. in: 2013 IEEE International Conference on robotics and automation 2013:1153-9.

19. Pino M, Boulay M, Jouen F, et al. "Are we ready for robots that care for us?" Attitudes and opinions of older adults toward socially assistive robots. Front Aging Neurosci 2015;7:141.

20. Darragh M, Ahn HS, MacDonald B, et al. Homecare Robots to Improve Health and Well-Being in Mild Cognitive Impairment and Early Stage Dementia: Results From a Scoping Study. J Am Med Dir Assoc 2017;18:1099.e1-4.

21. O'Brien BC, Harris IB, Beckman TJ, et al. Standards for reporting qualitative research: a synthesis of recommendations. Acad Med 2014;89:1245-51.

22. Tsui KM, Yanco HA. Design challenges and guidelines for social interaction using mobile telepresence robots. Reviews of Human Factors and Ergonomics 2013;9:227-301.

23. Lorish CD, Maisiak R. The face scale: a brief, nonverbal method for assessing patient mood. Arthritis Rheum 1986;29:906-9.

24. Almeida OP, Almeida SA. Short versions of the geriatric depression scale: a study of their validity for the diagnosis of a major depressive episode according to ICD-10 and DSM-IV. Int J Geriatr Psychiatry 1999;14:858-65.

25. Sandelowski M. Whatever happened to qualitative description? Res Nurs Health 2000;23:334-40.

26. Kroenke K, Spitzer RL, Williams JB. The patient health Questionnaire-2: validity of a two-item depression screener. Med Care 2003;1:1284-92.

27. Nomura T, Suzuki T, Kanda T, et al. What people assume about humanoid and ANIMAL-TYPE robots: cross-cultural analysis between Japan, Korea, and the United States. Int. J. Human. Robot. 2008;05:25-46.

28. Eyssel F, Kuchenbrandt D. Social categorization of social robots: Anthropomorphism as a function of robot group membership. $\mathrm{Br} \mathrm{J}$ Soc Psychol 2012;51:724-31.

29. Pearson Y, Borenstein J. Creating "companions" for children: the ethics of designing esthetic features for robots. Al Soc 2014;29:23-31.

30. Lincoln YS, Guba EG, Pilotta JJ. Naturalistic inquiry. California: Sage Publications, 1985: 9. 438-9. 